\title{
OVERTOPPING FLOW PROPERTIES CHARACTERIZATION IN LABORATORY AND PROTOTYPE THROUGH THE COMBINATION OF NON INTRUSIVE INSTRUMENTAL TECHNIQUES
}

\author{
A. Llana ${ }^{1}$, R. Molina ${ }^{1,2}$, A. Camarero ${ }^{2}$, A. Campos ${ }^{3}$, A. Alises ${ }^{1}$, J.D. López ${ }^{4}$ \\ Overtopping events may cause different failure modes depending on overtopped flow characteristics. Most of the \\ studies about overtopping hazard analysis link the damages caused by the overtopping event to its mean overtopping \\ discharge (q), which provides no information about overtopped flow characteristics or its spatial distribution. In this \\ paper it is presented a non intrusive measurement system based on video imagery techniques and optical level sensors \\ (OLS), which aim is to obtain overtopped highly aerated flows' principal characteristics: velocity, volume, and \\ density, in order to deep in the knowledge of this phenomenon, and minimizing the damages that it may cause to \\ port's infrastructures and exploitation
}

Keywords: Overtopping; aerated flows; Instrumental techniques;

\section{INTRODUCTION AND MOTIVATION}

In the last 10 years, port's infrastructures have shown a clear trend to grow seawards, looking for greater drafts at deeper waters with the aim of giving service to a fleet that continuously increases its dimensions. Within this context, defense structures have a remarkable role due the economic impact that they have in the total cost of the projects, and the technical challenge that they represent for its construction.

The high cost of a meter length of sea defense makes necessary to exploit the calm waters placed landwards in order to profit the inversion of its construction. As a consequence of it, some port's activities placed adjacent to seawalls are exposed to severe maritime climate action, and therefore overtopping events are more likely to occur affecting vulnerable areas where important economic activities take place.

Overtopping may cause different failure modes depending on flow characteristics; it is known that green water is associated to higher damages than white water or spray (Eurotop 2007). In order to cope with overtopping hazards next three actions should be always to be taken into account (Allsop 2005):

- Move human activities.

- Accept occasional hazards.

- Increase defense standards.

Traditionally coastal engineering has focused on increasing the protection standards. These acts derive on important material costs which in some cases can make the project economically unfeasible.

Taking the previous paragraphs into account, the authors of this paper would like to highlight the importance of the first two responses to overtopping hazards on port's exploitation and design. The first one, "move human activities", could be expressed as changing the activity to a less vulnerable one against overtopping. This is to say, port's activity management. In the case of the second one, "accept occasional hazards", it is necessary to quantify the consequences of overtopping hazard in order to decide whether are assumable or not, that is to say quantify the risk and determine if is there a need to take preventive or corrective actions. (Figure 1).

The combination of these two first logical responses is risk management. This concept aims to help into the making decision process bounding the risk assumed and optimizing the exploitation of port's activities and structural design. A first approach to risk management is PORMAT, a general methodology to introduce overtopping risk management in port's exploitation and design (Alises A. et al 2012) which is applied with a software in matlab® to facilitate its application by final users.

\footnotetext{
${ }^{1}$ Harbour Research Laboratory (HRL). Chair Pablo Bueno, Technical University of Madrid. Calle del Profesor Aranguren s/n. 28040, Madrid (Spain). (allana@caminos.upm.es, rmolina@caminos.upm.es, a.alises@caminos.upm.es)

${ }^{2}$ Civil Engineering \& Transport Department. Technical University of Madrid. Calle del Profesor Aranguren s/n. 28040, Madrid (Spain). (alberto.camarero@,caminos.upm.es)

${ }^{3}$ University of Castilla-La Mancha. Edif. Politécnico. Avda. Camilo José Cela s/n. 13071 Ciudad Real (Spain). (alvaro.campos@uclm.es)

${ }^{4}$ Public Organism of Ports of Spain. Branch of Development and Research. Avd. Del Partenón, 10, 28042, Madrid, spain. (jdamian@puertos.es)
} 


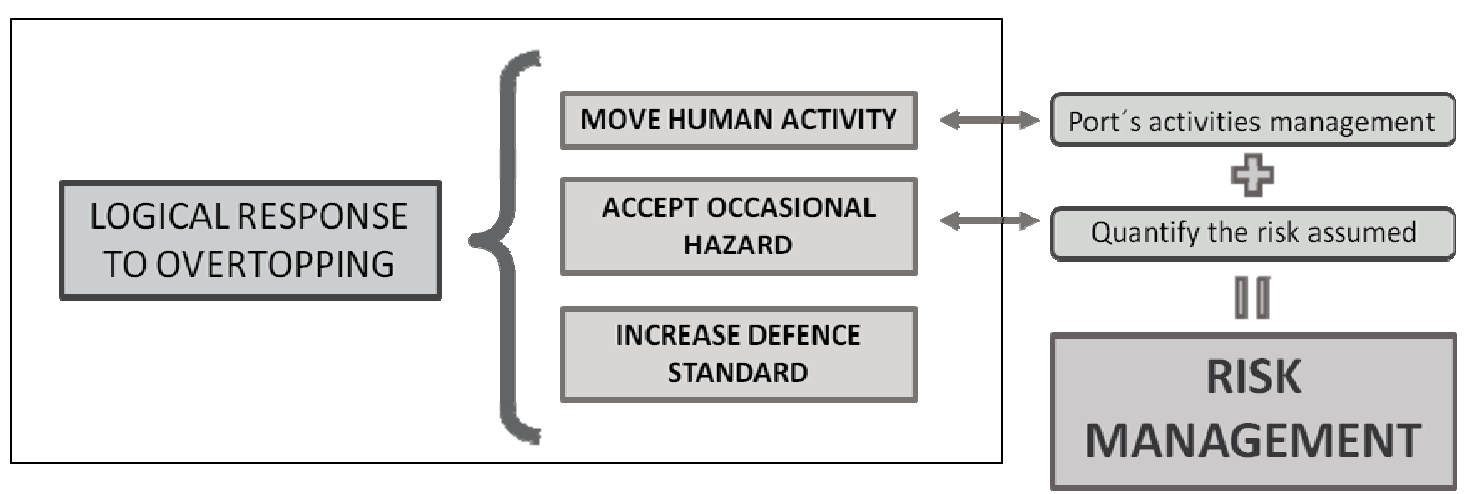

Figure 1. Logical response to overtopping hazards and its link with the concept of risk management.

A general description of the risk associated to a failure mode is defined as the product of three terms; Cost, Vulnerability and Probability (Gómez, R. 2012).

$$
\text { Risk }=\text { Cost } \times \text { Vu ln erability } \times \text { Probability }
$$

Where cost represents the expenses needed to restore the normal operational status of the infrastructure or the activities, probability is the probability associated to a failure mode, and vulnerability is the degree of affection to the material assets and to the activities.

As mentioned in previous paragraphs, overtopping may cause different failure modes depending on its characteristics. Therefore two out of the three terms present in equation 1 (probability and vulnerability) depends on the goodness of overtopping characterization.

Overtopping is a consequence of fluid-structure interaction. These events are governed by complex physical processes that involve both structure's parameters and maritime climate. The result of this interaction is a mass of air-water mixture passing over the sea defense's crest, whose properties: volume, density and velocity, evolves spatially and temporally affecting, the adjacent vulnerable area.

Overtopping hazards are not just associated either to mean flow, or accumulated overtopped volumes (Besley 1999). The terms involved in the failure mode's equations derived from overtopping events are density and flow velocities, that is to say, kinetic and potential energy

NIOVE PROMES project is the development of a non intrusive overtopping measurement system based on the combination of Optical Level Sensors (OLS) and video imagery techniques (Llana, A. et al 2011). The main goal of this project is to characterize overtopping through the measurement of velocity, density and volume of the overtopped flow, and the analysis of its spatial and temporal distribution. This project aims to fill the lack of knowledge between fluid-structure interaction and overtopping hazard analysis, providing variables of the overtopped air-water mixture to be correlated against both, maritime climate and overtopping hazards parameters.

This project is being realized by HRL in collaboration with the Public Organism of Ports of Spain. The HRL's research work is focused in three branches; the development of non intrusive measurement systems, the improvement and standardization of lab test's material and methods, and the inclusion of reliability and risk concepts on different stages of the project life. 


\section{MAIN OBJECTIVES}

NIOVE PROMES aims to be suitable for both lab tests and prototype overtopping measurement. At this stage of the project, works are focused on the development of the methodology and the design of the instrumental setting. Therefore different physical models have been designed in order validate the proposed methodology against different types of overtopping events.

Main objectives of this paper are summarize as follows:

- Develop of the methodology which should be applied in order to obtain overtopping flow properties characteristics (velocity, density and volume).

- Design the instrumental setting.

- Synchronize the instrumental system.

- Design a 2-D physical model.

\section{OVERTOPPING MEASUREMENT TECHNIQUES}

Overtopping has been widely studied in the last years. Extensive research about overtopping has been performed both in small and large scale lab tests such as VOWS, OPTICREST. CLASH project is probably the main reference on overtopping study, within this project, important advances have been done following different lines: obtaining new methods for mean overtopping discharge assessment (Verhaeghe H 2004); including new model and prototype's experimental data on available formulae in order to make it more accurate; evaluating overtopping hazards (Bouma et al. 2004); and Organizing all the information from experimental test realized both in CLASH PROJECT and in previous research works in a single data base (Verhaeghe $\mathrm{H}$ et al 2003).

Traditionally overtopping has been studied using the mean overtopping discharge as the principal key response. This variable gives aggregated information of overtopping's frequency and volume during a sea state. Therefore, given a mean overtopping discharge value, is not possible to determine whether overtopping events are small and frequent, or rare but with a high volume associated instead. As a consequence mean overtopping discharge may be valid to analyze overtopping events from a qualitative point of view, but is not sufficient by itself to characterize it.

With the aim acquiring deeper knowledge of overtopping events, several instrumental techniques have been developed and applied in the last decade to overtopping analysis, both in lab and prototype tests (Schüttrumpf H. et al 2002; Pullen T. et al 2003; Troch P. et al 2004; De Rouck J. et al 2004; Briganti R. et al 2005; Pullen T. et al 2009). The use of these techniques has allowed both obtaining additional overtopping key responses, and modifying previous existing ones in order to obtain a better characterization of overtopping events (see "modified mean overtopping discharge $\left(q_{\text {new }}\right)$ " Campos, A et al 2012).

Video imagery techniques have been already successfully applied for studying flow structure interaction (Molina, $\mathrm{R}$ et al. 2008). The development of a new non linear approach to solve the geometrical problem (Molina, R 2006) has allowed to obtain direct measurements of processes with a high spatial distribution. In addition, statistical image analysis and other video imagery techniques such as time-stack, allow to obtain statistical information that cannot see the naked eye. All this techniques have been integrated within ZEUS project which is being developed by UGR-HRL since 2005.

Despite the potential that video imagery techniques have shown when dealing with high spatial and temporal distributed phenomena such as overtopping events, it is not capable by itself, to obtain information about the intrinsic characteristics of the overtopped flow. Therefore this technique needs to be combined with an Optical Level Sensor (OLS) system which can be placed inside the mass of airwater mixture, in order to achieve information from the inside of the overtopped volume and measure its intrinsic properties.

OLS (Figure 2) is a digital output instrument which indicates whether it is humid (1), or dry (0). Its operation is based on the total internal reflection principle. This type of sensor is being applied in different branches of the engineering such as automotive or medical industries. The typical technical specifications of OLS are following: 


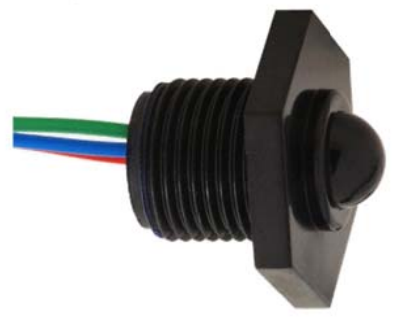

Figure 2. Optical Level Sensor. (OLS)

- Response time: Rising liquid level $50 \mu \mathrm{s}$. Falling liquid level $1 \mathrm{~s}$ (max in ethanol). Response in other liquids depends on viscosity.

- Operating temperature: from $-25^{\circ} \mathrm{C}$ to $80^{\circ} \mathrm{C}$.

- Material: Polysulphone

- Dimensions: Dome $3.5 \mathrm{~mm}$ (radius); Threat M12x1 mm; Hexagon $19 \mathrm{~mm}$.

Several of its characteristics are of interest for the measurement of overtopping events; high velocity of response; robustness is granted by its made of materials; reliability against maritime climate action, which is being tested by Barcelona's Port Authority (APB) since 2010; small size (19 x 19 x 12 $\mathrm{mm}$ ) which ensures its non intrusiveness at prototype scale; and low acquisition and maintenance cost.

\section{LAB TESTS \& INSTRUMENTAL SETTING}

Lab tests have been carried out at the wave flume of the Harbour Research Laboratory of the Technical University of Madrid (52 m long, $1 \mathrm{~m}$ wide and $1.60 \mathrm{~m}$ high), where wave conditions have been generated by piston paddle wave maker with dynamic absorption system on.

Wave flume's floor has been modified to a mild slope seabed (1:100) in order to obtain different wave breaking conditions and higher wave heights at the front of the vertical wall. The physical model has been placed at a distance of $27 \mathrm{~m}$ from the wave maker as shown in Figure 3. The sea defense tested is a vertical wall made of expanded polyethylene, which dimensions $(0.25 \mathrm{~m}$ long by $1 \mathrm{~m}$ wide and $0.53 \mathrm{~m} \mathrm{high)} \mathrm{correspond} \mathrm{to} \mathrm{an} \mathrm{experiment} \mathrm{scale} \mathrm{of} \mathrm{1:50.} \mathrm{A} \mathrm{partially} \mathrm{submerged} \mathrm{overtopping}$ reception tank has being placed $0.5 \mathrm{~m}$ behind the model. The water has being guided to the reception tank by a mild slope, which has been gridded to obtain quantitative information of overtopping falling distance by using video imagery techniques.

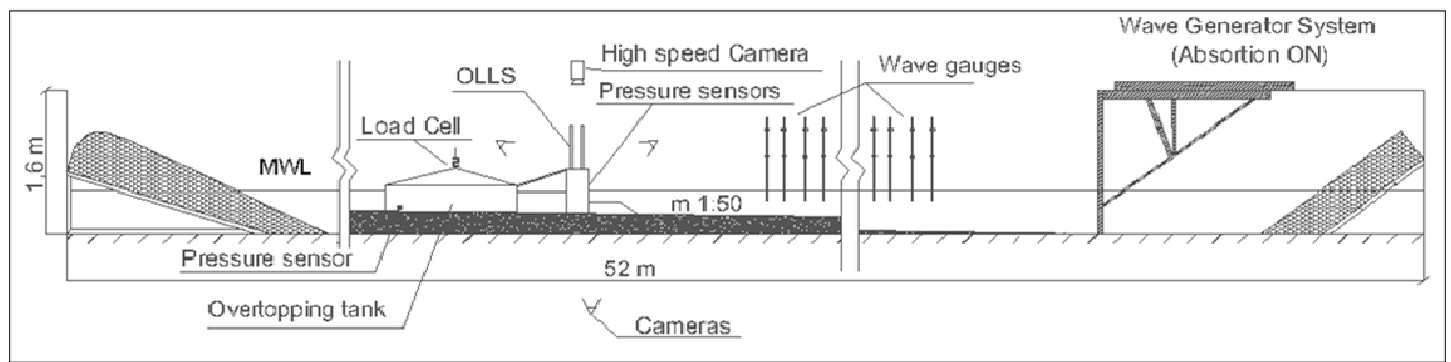

Figure 3 Test scheme of the experiments realized at HRL's wave flume. It is shown the instrumental setting developed for overtopping measurement (OLLS and video image) and the conventional instrumentation applied.

Wave conditions were established in order to obtain different types of wave breaking and overtopping (green and white water). A total of 12 wave conditions have been performed (see Table 1). Four Jonswap spectra have been generated with a range of wave heights from 0.05 to $0.12 \mathrm{~m}$, and a range of periods from 1.09 to $3.29 \mathrm{~s}$, each of this wave spectra has been tested under two different drafts, $0.25 \mathrm{~m}$ and $0.28 \mathrm{~m}$ at the toe of the structure. 


\begin{tabular}{|c|c|c|c|c|c|}
\hline & $\mathrm{H}_{\mathrm{mo}} / \mathrm{Rc}[-]$ & $\mathrm{Rc}[\mathrm{m}]$ & $\mathrm{h}_{\text {toe }}[\mathrm{m}]$ & $\mathrm{H}_{\mathrm{mo}}$ toe $[\mathrm{m}]$ & $\mathrm{T}_{\mathrm{p}}$ toe $[\mathrm{m}]$ \\
\hline WC1 & 0.40 & 0.2850 & 0.2500 & 0.1270 & 1.7200 \\
\hline WC2 & 0.40 & 0.2850 & 0.2500 & 0.1270 & 3.2900 \\
\hline WC3 & 0.40 & 0.2850 & 0.2500 & 0.1000 & 1.4000 \\
\hline WC4 & 0.40 & 0.2850 & 0.2500 & 0.1000 & 2.6200 \\
\hline WC5 & 0.30 & 0.2850 & 0.2500 & 0.0730 & 1.0900 \\
\hline WC6 & 0.30 & 0.2850 & 0.2500 & 0.0730 & 1.9500 \\
\hline WC7 & 0.50 & 0.2500 & 0.2850 & 0.1270 & 1.7200 \\
\hline WC8 & 0.50 & 0.2500 & 0.2850 & 0.1270 & 3.2900 \\
\hline WC9 & 0.40 & 0.2500 & 0.2850 & 0.1000 & 1.4000 \\
\hline WC10 & 0.40 & 0.2500 & 0.2850 & 0.1000 & 2.6200 \\
\hline WC11 & 0.20 & 0.2500 & 0.2850 & 0.0500 & 0.8200 \\
\hline WC12 & 0.20 & 0.2500 & 0.2850 & 0.0500 & 1.3300 \\
\hline
\end{tabular}

The overtopping tests performed at the HRL's wave flume have been over instrumented with the aim to compare and correlate the results obtained by the proposed combination (OLS and video imagery techniques), against conventional overtopping measurement systems. In order to do so the six different measurement systems employed and the wave paddle movements have been recorded synchronously.

The sample frequency of all instruments has been $1000 \mathrm{~Hz}$ except high speed cameras which have recorded at $100 \mathrm{fps}$ due to computer's capacity. In order to ensure the synchronization between high speed video cameras and the rest of the measurement systems, these first ones have worked on external trigger mode and trigger signal has been also recorded at $1000 \mathrm{~Hz}$ sample rate.

\section{Conventional instrumental setting}

Overtopping events have being measured by the overtopping reception tank. Overtopped water has being measured both in volume, by a pressure transducer placed at the bottom of the tank, and in weight by the usage of a load cell. In order to obtain best quality records, $0.05 \mathrm{~m}$ thick of open cell polymeric porous media (Cabrerizo 2010) was placed at the bottom of each of the nine overtopping reception tank's cell, which acted as a damper minimizing the oscillations of the free surface within the reception tank, and therefore minimizing the noise at the pressure transducer's signal due to the water column oscillation.

Wave impacts have been measured with 9 pressure transducers placed on the front wall of the physical model. The records obtained will provide information about wave breaking conditions and will allow to correlate them with the type of overtopping event.

A total of 8 resistive gauges have been installed along the wave flume (see Figure 3 ) in order to record the free surface during the tests. The distance between the 4 resistive gauges of each group, a first group placed next to the model and the other next to the paddle, has being determined following Mansard's criteria to separate incident and reflected waves (Mansard 1981).

Finally, all tests realized have been recorded with an IP camera with a general view of the model to control the experiments performed and recreate them if needed.

\section{NIOVE PROMES instrumental setting}

The proposed instrumental system consists of a total of 48 OLS and 2 high speed video cameras.

OLS have been placed over the crest of the physical model in 4 groups of 12 OLS, which are housed within hydrodynamic shaped beams in order to affect as less as possible the overtopped flow. These groups have been installed in a staggered form, two of them next to the front wall of the model, and the other two $0.15 \mathrm{~m}$ behind. Attending to the vertical distribution, the instrumental density is not constant along the beams in which are placed the OLS; the first $0.15 \mathrm{~m}$ of each beam is instrumented with 6 OLS separated each $0.025 \mathrm{~m}$, and the other six dist $0.05 \mathrm{~m}$ from each other. The aim of this vertical distribution is focusing the measurements on those areas in which the boundary between water and air-water mixture is expected.

Two high speed video cameras have been placed in a zenithal and lateral view. These cameras have been controlled using ZEUS, an open source program that integrates camera management, acquisition tasks and post-processing techniques, which is being developed by the HRL.

Finally in order to obtain best quality video post-processing results, light conditions have been controlled, and model's crest and flume's wall painted in mild gray to make the background's color neither help nor harm any of the three RGB channels of video imagery acquisition. 


\section{METHODOLOGY}

The methodology proposed in this paper aims to obtain overtopping flow properties both in laboratory and in prototype (Figure 4). At this first stage of the project the methodology will be applied in laboratory tests to calibrate and improve the instrumental setting. In addition, NIOVE PROMES measurements will be compared against laboratory conventional techniques, and overtopping kinetic and potential energy will be calculated in order to estimate overtopping hazards.

\section{Event by event analysis}

Overtopping event by event analysis aims to obtain the principal variables (velocity density and volume) for each individual event. As these variables evolve in time and space, two different methods will be applied; promenade in time analysis and promenade in space analysis.

Promenade in time analysis obtains information of a cross section placed over the crest of the physical model. This cross section is defined by OLS's emplacement (see cross section BB' in Figure 5). In order to obtain additional information needed for measuring velocity and volume, two additional cross sections, perpendicular to the first one (sections AA' and CC'), are analyzed by time-stack ${ }^{5}$ video imagery technique.

Promenade in space analysis will obtain information of the area of interest (AOI) placed over the crest of the physical model but not its evolution during time, this is to say, at certain instant of time (see Figure 5).

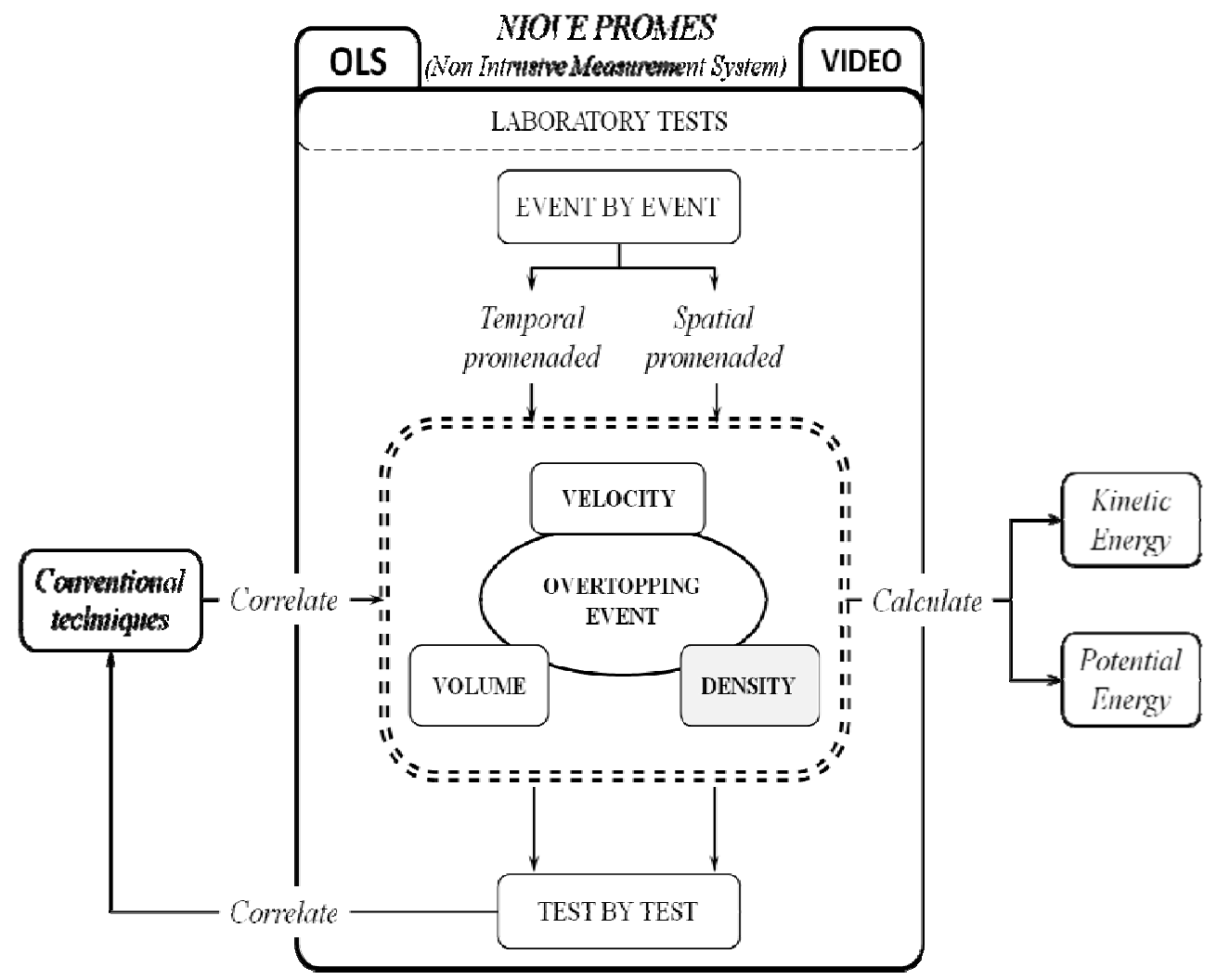

Figure 4. Proposed methodology to obtain overtopping flow properties: velocity, density and volume, by using NIOVE PROMES instrumental setting.

\footnotetext{
${ }^{5}$ Time-stack video imagery technique consists in obtaining the evolution of a line of pixel along a video sequence.
} 

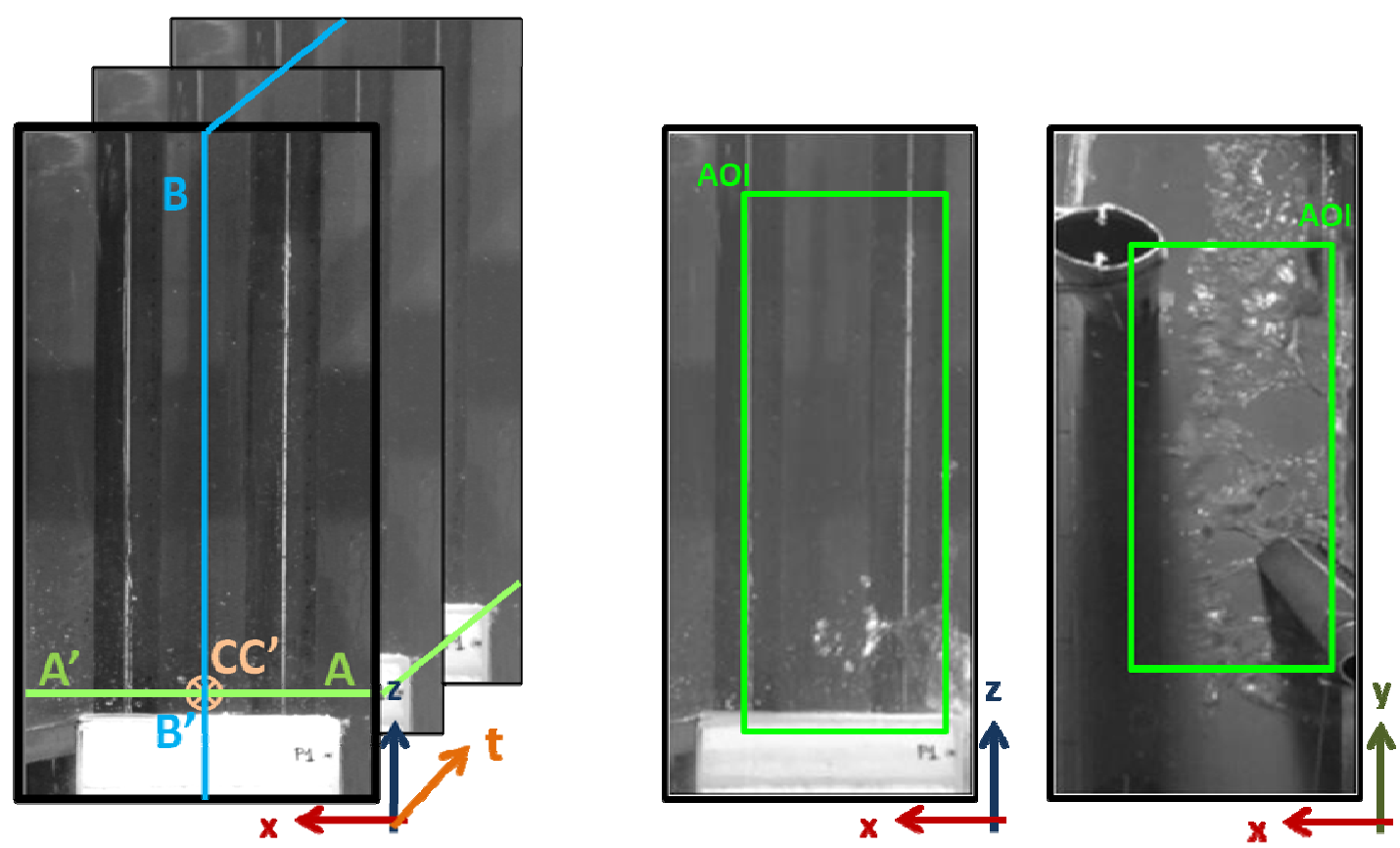

Figure 5. On the left, a lateral view of the physical model test and the cross sections $\left\{A A^{\prime}, B^{\prime}\right.$ ' and CC'\} used to obtain promenaded in time variables. On the right it is shown the lateral and zenithal view of the model with the area of interest (AOI) analyzed to obtain promenaded in space variables.

Promenade in time variables

Promenaded in time $\mathrm{x}$ component velocity will be estimated by time-stacking across AA' section. The result of a time stack is shown in Figure 6, where each group of white pixels represents an overtopping event, and $\mathrm{x}$-axis and $\mathrm{y}$-axis indicates time and length respectively. The $\mathrm{x}$ component velocity of an overtopping event will be therefore estimated as the slope of the line that best fits in the overtopping events recorded by time-stack video imagery technique.

$$
v_{x}=\frac{d x_{i}}{d t}=m \equiv[L][s]^{-1}
$$

Promenaded in time volume will be obtained by time-stacking across BB' and $\mathrm{CC}^{\prime}$ 'cross sections. In order to obtain the projection of the overtopped volume against the horizontal and vertical plane, it is necessary to multiply $\mathrm{x}$-axis of the time-stacks $\mathrm{BB}^{\prime}$ and $\mathrm{CC}^{\prime}$ by the $\mathrm{x}$ component velocity calculated previously (equation 3 ).

$$
\text { OVolume }_{\text {projection }}=\left\{\begin{array}{c}
\text { TimeStack }_{x} \times v_{x} \equiv[s] \times[L][s]^{-1}=[L] \\
\text { TimeStack }_{y} \equiv[L]
\end{array}\right.
$$

Once overtopped volume projections have been obtained, it is possible to estimate the promenaded in time volume by multiplying both projection. 
Timestack Obtained
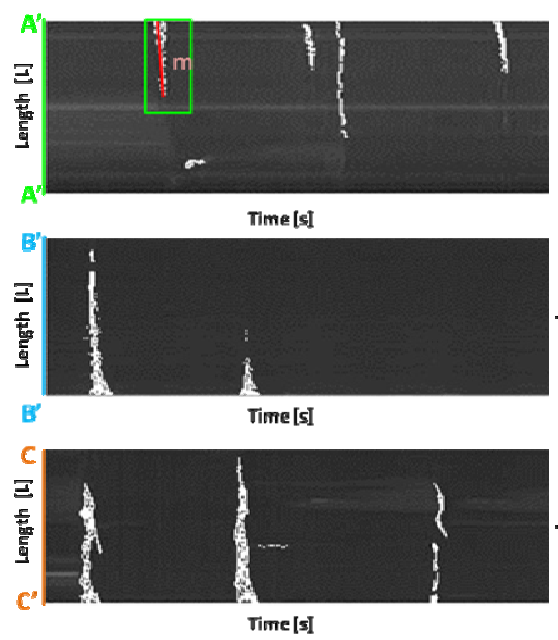

Overtopping volume projections

$$
v_{i}=\frac{d x_{i}}{d t}=[L][s]^{-1}
$$
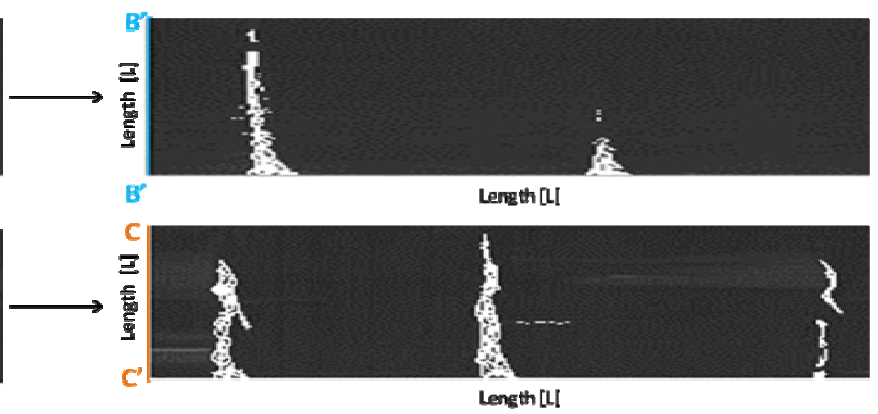

Figure 6. Time stacks obtained from each of the sections AA', BB', and CC'. On the right side of the figure, it is shown the methodology applied to obtain $x$ component velocity and overtopped volumes projections from the previously obtained time stacks.

As mentioned before, OLS are necessary to obtain additional information from the inside of the overtopped volume such as density.

Figure 7 shows some examples of a group of OLS's records where $\mathrm{x}$-axis and $\mathrm{y}$-axis indicates time and OLS position respectively, and each row is an individual OLS record (blue dot indicates that it is humid, nothing that it is dry). The figure on the left shows that in the recorded overtopping event, the overtopped flow was highly aerated (white water) as it is indicated by the empty gaps recorded by certain OLS units. On the other hand the figure on the right shows that during the overtopping event, no gaps where recorded by OLS and the air-water boundary is perfectly defined, which indicates a non aerated overtopping event or "green water".

\section{White water overtopping}

\section{Green water overtopping}
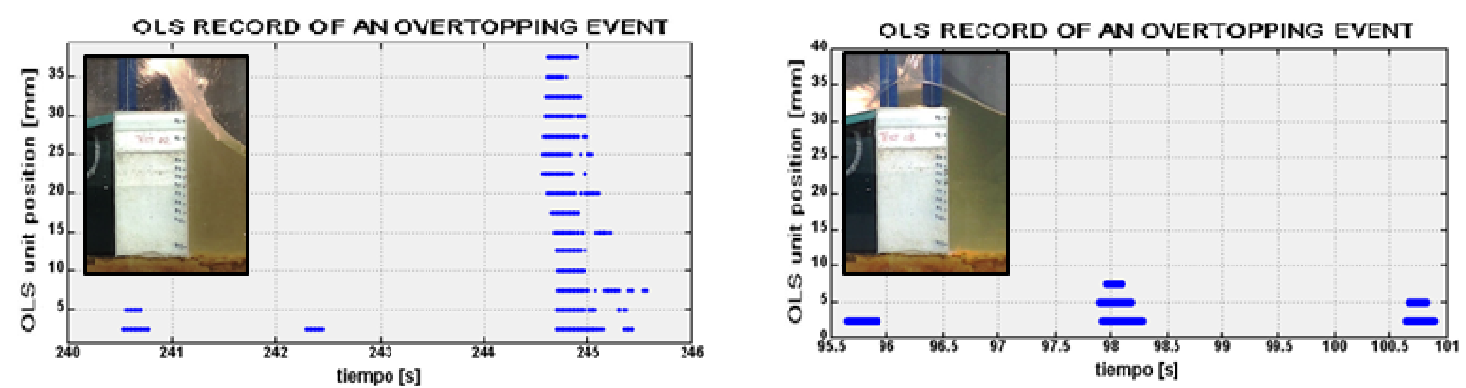

Figure 7. Two snap shots of a OLS time series measurement. x-axis and y-axis indicates time and OLS position respectively, each row is an individual OLS record (blue dot indicates that it is humid, none that it is dry)

Promenaded in time density will be estimated by the density factor, which is defined as the relationship between the aerated flow volume and the volume of water. The density factor will be obtained following next two methods:

- Dividing the overtopped volume obtained by the video imagery technique previously defined, by the volume of water, registered by overtopping tank. 
- Obtained by a group of OLS's record as the fraction of the number of OLS humidify over the number of OLS within the overtopped volume (see Figure 8), which will be determined by time stack as described before.

In order to obtain the density factor directly from OLS measurements, the values calculated by these two methods will be compared to obtain a fit for OLS measurements.

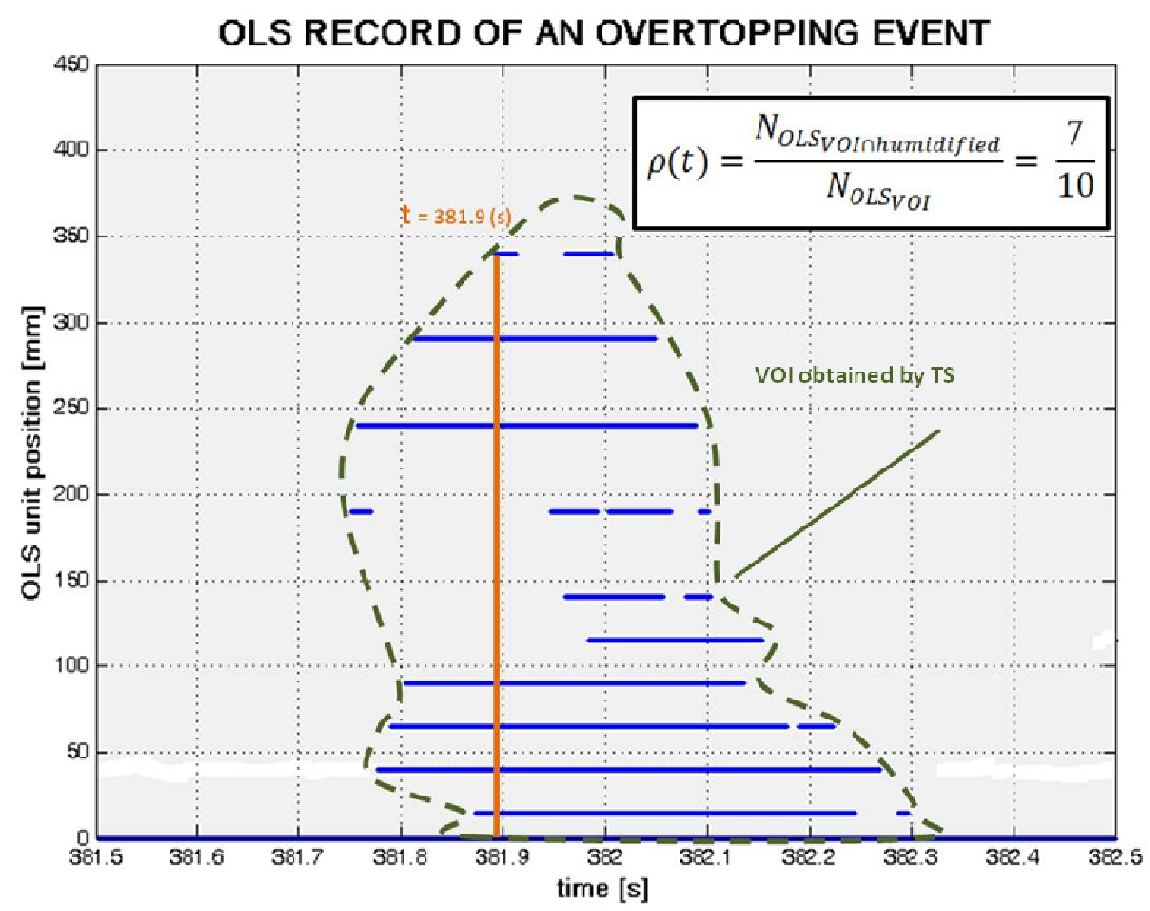

Figure 8. OLS measurement of an overtopping event in which it is shown the methodology applied to obtain the density factor.

Promenade in space variables

Promenaded in space velocity will be estimated as the evolution of the region identified by video imagery segmentation techniques.

In the case of obtaining the promenaded in space volume, it will be estimated by multiplying lateral and zenithal overtopped volume projections as described in promenaded in time method. Main difference between this method and the previously described is that, in the first one, there is no need to multiply by the $\mathrm{x}$ component overtopping velocity to obtain overtopped volume projections.

Promenaded in space density factor will be estimated following an analogous procedure to promenaded in time density. In this case OLS's measurements are given by the four groups of OLS at an instant of time. Therefore OLS will provide a 3-dimensional grid, which nodes are coincident with OLS's locations, indicating which of the nodes are humid (1) or dry (0). The density factor will be calculated by the following next two methods in order to obtain a fit for OLS measurements:

- Dividing the overtopped volume by the volume of water registered by overtopping tank.

- As the fraction of the number of OLS humid over the number of OLS within the overtopped volume.

\section{Test by test analysis}

Test by test analysis is meant to be the immediate consequence of event by event analysis. Once overtopping flow properties can be obtained for each of the overtopping events, test by test analysis will analyze these variables statistically. Therefore it will be possible to compare the result obtained by the application of the presented methodology against the available experimental data, which results are usually given promenaded both in time and space.

The instrumental setting designed allows, by the use of video imagery variance analysis, to obtain the overtopping vulnerable area, and therefore the overtopping falling distance. 
Kinetic and potential energy

In the introduction and motivation of the present paper, it has been pointed out the necessity of including risk management in port's exploitation and design. It is known that overtopping consequences are not strictly associated either to mean flow, nor to the accumulated overtopped volume.

Last step of the presented methodology is therefore to obtain overtopping kinetic and potential energy, which are function of the velocity and density of the overtopped flow, and can be expressed mathematically as (Ryu et al (2007)):

$$
\begin{gathered}
E P=\frac{1}{t_{g e}-t_{g s}} \cdot \int_{t_{g s}}^{t_{g e}} \int_{0}^{h}(1-\alpha) \rho g z . d z . d t \\
K E=\frac{1}{t_{g e}-t_{g s}} \cdot \int_{t_{g s}}^{t_{g e}} \int_{h_{0}}^{h}(1-\alpha) \rho \frac{\left(u^{2}+w^{2}\right)}{2} \cdot d z . d t
\end{gathered}
$$

Where $\alpha$ is the promenade in time density factor and PE and KE are the time-averaged potential and kinetic energy respectively. The terms tgs and tge indicates the duration of the overtopping event and, and $\mathrm{U}$ and $\mathrm{W}$ are the mean velocities in the $\mathrm{x}$ and $\mathrm{z}$ directions.

\section{FURTHER RESEARCH}

In the present paper NIOVE PROMES project has been presented. The description of its instrumental setting and the methodology applied to obtain overtopping flow properties (velocity, density and volume) has been done. And finally, conventional instrumental setting and lab tests in which NIOVE PROMES will be applied, have been described.

The HRL will keep working on the measurement of overtopping events with the aim of getting deeper knowledge of this phenomenon, and how to minimize the hazards that it may cause to port's infrastructures and exploitation.

NIOVE PROMES further research may be summarized in the following steps:

1. Apply the presented methodology to different sea defense's typologies, and compare its results against conventional instrumentation.

2. Use a set of measurements from all of the instrumental techniques applied for numerical model calibration.

3. Adapt the laboratory instrumental setting to prototype, and obtain measurements of real overtopping events.

4. Determine overtopping vulnerable areas, and provide necessary data to calculate the risk associated to overtopping events.

\section{ACKNOLEDGMENTS}

The authors are indebted to the Branch of Development and Research of the Public Organism of Ports of Spain by funding received and partial support. We also would like to acknowledge to Delft Hydraulics, and particularly to Dr. Marcel Van Gent by additional information supplied.

\section{REFERENCES}

Alises, A., Molina M., Gómez R., Pery P. (2012) Overtopping Hazards to port activities. Application of a new methodology to risk management (POrt RIsk MAnagement Tool). In press.

Allsop, N.W.H., (2005). Report on hazard analysis, CLASH WP6 report, HR Wallingford, United Kingdom.

Besley, P., (1999). Overtopping of seawalls - design and assessment manual, R \& D Technical Report W178, Environment Agency, Bristol, United Kingdom, ISBN 185705069 X.

Bouma, J.J., Schram, A., François, D., (2004). Report on socio-economic impacts, CLASH WP6 report, Ghent University, Belgium.

Briganti R., Bellotti G., Franco L., De Rouck J., Geeraerts J., (2005) "Field measurements of wave overtopping at the rubble mound breakwater of Rome - Ostia yacht harbor". Elsevier Science BV, Coastal Engineering. 
Cabrerizo et al. 2010 "Control of porosity, reflection and transmisión coefficients using polymeric porous media and their application in testing physical models" Coastlab 2010. Barcelona.

Campos, A., Molina, R., Llana, A., Alises, A., Gomez, R., Castillo, C. (2012). Overtopping characterization for the elaboration of vulnerability maps in ports facilities. International Conference on Coastal Engineering. 1-7 July Santander, Spain. (in press).

EurOtop Overtopping Manual (2007). Wave Overtopping of Sea Defences and Relates Structures Assessment Manual. Eds.Pullen, T., N.W.H Allsop, T. Bruce, A. Kortenhaus, H. Schüttrumpf \& J.W. van der Meer. www.overtopping-manual.com.

Gómez, R., Molina, R., (2012) Guía para el cálculo de la Fiabilidad y determinación del Riesgo en las Obras Marítimas e Instalaciones Portuarias mediante la aplicación de técnicas probabilistas. Puertos del Estado. Universidad Politécnica de Madrid.-in press.

A.Llana et al (2011), "Técnicas de video imagen y sensores ópticos, las acciones del rebase" Proceedings of the 11th Jornadas de Puertos y Costas. Las Palmas de Gran Canaria, Spain

Mansard E.P.D., Funke E.R. (1981) "The measurement of incident and reflected spectra using a least squares method". Coast. Eng. 1980, ASCE, New York, 154-172.

Molina, R., Ortega, M., Moyano, J., Losada, M. (2008) "Analysis of the wave interaction with rubblemound breakwaters using video imagery techniques". Mediterranean Days PIANC, Palermo

Molina, R. (2006) Resolución del problema geométrico en video imagen. Centro Andaluz de Medio Ambiente, Universidad de Granada.

Pullen, T., Allsop, W., Bruce, T., Geeraerts, J., 2003. "Violent wave overtopping - CLASH field measurements at Samphire Hoe". Proc. Conf. Coastal Structures, Portland, Oregon, USA, pp. 469480.

Pullen T., Allsop W., Tom Bruce, Jonathan Pearson. 2009 "Field and laboratory measurements of mean overtopping discharges and spatial distributions at vertical seawalls" Coastal Engineering 56 page $121-140$

Julien De Rouck, Björn Van de Walle, Peter Troch, Jentsje van der Meer, Luc Van Damme, Josep R. Medina, Marc Willems, and Peter Frigaard (2007) Wave Run-Up on the Zeebrugge Rubble Mound Breakwater: Full-Scale Measurement Results. Journal of Coastal Research: Volume 23, Issue 3: pp. $577-583$.

Ryu Y, Chang K-A, (2007a) Green water void fraction due to breaking wave impinging and overtopping. Exp Fluids 45:883-898

Schüttrumpf H., Möller J., Oumeraci H. 2002 "Overtopping flow parameters on the inner slope of seadikes". 28 th Int. Conf. On Coastal Engineering. Cardiff, UK.

Troch P., Geeraerts J., Van de Walle B., De Rouck J., Van Damme L., Allsop N.W.H., Franco L., (2004), Full scale wave overtopping measurements on the Zeebrugge rubble mound breakwater, Coastal Engineering. Volume 51, Issue 7, Pages 609-628.

Verhaeghe H., van der Meer J., Steendam G.J., Besley P., Franco L. (2003); Wave overtopping database and a first neural network prediction method. Proceedings Coastal Structures 2003, Portland, Oregon, USA.

Verhaeghe H (2004) "Neural Network Prediction of Wave Overtopping at Coastal Structures" Doctoral Dissertation, Gent University. 